Western University

Scholarship@Western

Department of Economics Research Reports

Economics Working Papers Archive

1973

\title{
The Managerial Enterprise: A Model of Expected Payoffs and Some Empirical Results
}

John P. Palmer

Follow this and additional works at: https://ir.lib.uwo.ca/economicsresrpt

Part of the Economics Commons

Citation of this paper:

Palmer, John P.. "The Managerial Enterprise: A Model of Expected Payoffs and Some Empirical Results." Department of Economics Research Reports, 7307. London, ON: Department of Economics, University of Western Ontario (1973). 
Research Report 7307

THE MANAGERIAL ENTERPRISE: A MODEL OF EXPECTED PAYOFFS AND SOME

EMPIRICAL RESULTS

\author{
by \\ John Palmer *
}

*Assistant Professor of Economics, The University of Western Ontario. Helpful suggestions were received from David Scheffman and Donald McFetridge. 
The Managerial Enterprise: A Model of Expected

Payoffs and Some Empirical Results

The predominance of large, management controlled (vs. Owner controlled) firms in the U.S. is we11 documented [5, 13]. Discussions of this phenomenon have generally fallen into one or the other (but rarely both) of two distinguishable categories: theoretical and empirical. On the one hand intriguing theories of managerialism frequently with little or no empirical support, are presented by Marris [7], Williamson [14], Cyert and March [2], Monsen and Downs [10], and Berle [1], to name a few. On the other hand empirical results which are seldomly related to rigorously developed theory have been reported by Kamerschen [4], Monsen, Chiu, and Cooley [9], Larner [5], Elliot [3], and Palmer [12]. What I propose to do here is to put forth a simple model capturing much of the flavour of the theorizing done to date and then perform some comparative statics experiments with the model to obtain predictions which can be tested empirically.

I

Suppose a manager of a management controlled firm has the opportunity to increase his firm's pretax dollar profits by an amount equal to $\Delta \pi$. How much would such an action actually increase his utility? For the purposes of simplification, we can assume a separable and additive utility function and divide the sources of his increased utility into pecuniary and nonpecuniary. The pecuniary source, $\Delta \pi$, must first be multiplied by $\left(1-t_{\pi}\right)$ to allow for the corporate profits tax rate. Next it must be multiplied by $(1-s)$, where $s$ is the percentage of increased after tax profits skimmed off by stockholders other than the manager. In management controlled firms, one might expect $s$ to be somewhere between 0.90 and 0.99 . Finally, allowance must be made for 
personal income tax rates, so that the potential increase in utility resulting from pecuniary sources can be written as

$$
\Delta U=U\left(\Delta \pi\left(1-t_{\pi}\right)(1-s)\left(1-t_{p}\right)\right)
$$

Because, by increasing profits, the manager might also derive some utility from nonpecuniary sources, $\mathrm{N}_{i}$, we must also add this term to show his total expected increase in utility resulting from increasing pretax dollar profits by $\Delta \pi$.

$$
\Delta U=U\left(\Delta \pi\left(1-t_{\pi}\right)(1-s)\left(1-t_{p}\right)\right)+U\left(\Delta N_{i}\right)
$$

It may frequently be the case that $\Delta \mathrm{U}$ is not much greater than zero. Suppose $\Delta \pi=\$ 1,000$. If $t_{\pi}=0.50, s=0.90$, and $t_{p}=0.80$, all quite reasonable suppositions, then the manager can expect to receive only ten dollars for his efforts. And if the manager has been able to free himself from the shackles of the Protestant work ethic, he may completely discount the second term of (2), leaving him with very little increase in utility.

Weighed against this relatively small increase in utility, the manager may wish to consider alternative uses of the $\Delta \pi$ which might provide him with more utility, e.g., plush surroundings, company planes, vacations disguised as "business trips," lavish expense accounts, etc. Call the utility he might derive from these nonpecuniary sources $U\left(\Delta N_{d}\right)$. Subtracted from $U\left(\Delta N_{d}\right)$ must be his expected loss of utility, in a probability sense, if he were detected in such non-profit-oriented activities by the stockholders. These subtractions can be written as $-\mathrm{P}_{c}\left[U\left(\Delta \mathrm{Y}_{c}\right)+U\left(\Delta_{c}\right)\right]$, where $\mathrm{P}_{c}$ is the probability of his getting caught, $\Delta \mathrm{Y}_{c}$ is his expected loss of income if caught, and $U\left(\Delta \mathrm{N}_{c}\right)$ represents his expected loss of utility from nonpecuniary sources such as demotions and loss of status if caught by the stockholders. The manager's decision, then, is based on the following decision criterion: 
(3)

$$
U\left(\Delta \pi\left(1-t_{\pi}\right)(1-s)\left(1-t_{p}\right)\right)+U\left(\Delta N_{i}\right) \gtrless U\left(\Delta N_{d}\right)-P_{c}\left[U\left(\Delta \mathrm{Y}_{c}\right)+U\left(\Delta N_{c}\right)\right]
$$

To maximize his expected utility, the manager will select the activities associated with the larger side of inequality (3).

II

The very simplest theories of managerialism suggest that for management controlled firms, s should be very high and $P_{c}$ very low, making the left side of (3) very close to zero and less than the right side. As a result, managers of such firms are predicted, on the average, to report lower rates of return than managers of owner controlled firms. Such a prediction has not, in general, been verified empirically [3], [4], [5], [12]. If the model is increased in complexity slightly so that $\mathrm{P}_{\mathrm{c}}$ is assumed to increase significantly above zero only if "subnormal" profits are reported, then we can predict that managerial profit reduction should be less likely among frims with a low degree of monopoly power and should be observed primarily among those firms with a high degree of monopoly power. This prediction has been empirically verified [12], providing some support for the above model.

Carrying our comparative statics a little further, we can see that if managerial compensation is increasingly tied to stock options, stock warrants, etc., as indicated by Larner [5], Lewellyn [6] and Masson [8], then s should fal1, increasing the value of the left side of (3) and enticing managers to become more profit oriented in their behaviour. Some support for this prediction has been provided by Masson [8].

Finally, consider the effects of tax rate changes. If tax rates are cut, the left side of (3) becomes more attractive, and those managers who previously had selected the right side of (3) may see sufficient incentive to 
increase reported profits of their firms. In other words, after tax rates are reduced, management controlled firms are predicted to report greater increases in profit rates than are owner controlled firms, especially among the group of firms having a high degree of monopoly power. The reverse should hold for tax rate increases.

To test this prediction, firms from the Fortune 1ist of the 500 largest corporations in 1965 were studied. Each firm was classified as strong owner controlled (one party owned at least $30 \%$ of the common stock), weak owner controlled (one party owned between $10 \%$ and $30 \%$ ), or management controlled (the residual category; see [12], [13] for more details on the classificatory scheme). The firms were also grouped into four size classifications: the largest 125, the next largest 125, etc., to control for the possible effects of size. The monopoly power of a firm was measured by first estimating the height of the barriers to entry into each industry in which the firm sold goods or services and then weighting these estimates by the percentage of total revenue the firm derived from each industry in which it transacted business. This weighting scheme was utilized to take account of the multi-industry activities of most large firms

For each firm, two observations could be computed for the decade of the sixties. $\frac{(\pi / N w)_{64}+(\pi / N w) 65}{2}-\frac{(\pi / N w) 61+(\pi / N w) 62}{2}$ provides a measure of the effects of the tax rate decrease in the early sixties. $\frac{(\pi / N w)_{66}+(\pi / N w)_{67}}{2}-\frac{(\pi / N w) 68+(\pi / N w) 69}{2}$ takes account of the surtax enacted in 1968. Two-year averages were used to smooth out some of the randomness in single,

${ }^{1}$ Those for whom $P_{c}$ and $s$ are relatively low (i.e., managers of management controlled, high monopoly power firms) will receive an incentive to select the left side of (3) a little more often than previously. All firms will report increased profit rates in response to tax rate decreases, but this subset of firms will be likely to report even greater increases in profit rates as they become more profit oriented in their behaviour. 
annual observations. The observations were computed in the above fashion so that for both the tax rate increase and the tax rate decrease, the terms would be positive and the two observations could be pooled to increase the number of observations. In both cases the model of inequality (3) would predict that among firms with a high degree of monopoly power, management controlled firms should report larger changes in profit rates than owner controlled firms.

The test employed was that of simple statistical contrasts (or comparisons) with a correction factor for heteroscedasticity [11, p. 377]. There was one degree of freedom in the numerator, but because there were different numbers of observations in each ce11, Satterthwaite's approximation was used to estimate the degrees of freedom in the denominator (see $[11, \mathrm{p} .302]$ ). None of the contrasts involving the size classes was statistically significant. The results, of the remaining contrasts are presented in Tables 1 and 2 .

As predicted, the separation of ownership from control had no significant effect on firms with a low degree monopoly power. It appears that the struggle for survival is so intense among these firms that there is little or no scope for profit-reducing managerial discretion within them regardless of their type of control. Among firms with a high degree of monopoly power, weak owner controlled firms by themselves and in combination with management controlled firms reported significantly larger changes in profit rates than strong owner controlled firms. In this same group, management controlled firms reported larger (but not significantly so) changes than strong owner controlled firms; they also reported insignificantly lower changes than weak owner controlled firms.

There are several likely reasons for the observed effect that monopoly power alone had on profit rate responses to tax rate changes. One reason 
might be that type of control should not be ignored and that the separation of ownership from control creates the misleading impression that increased monopoly power by itself causes the observed differences of Tables 1 and 2 . A second reason might be that firms with higher degrees of monopoly power are in general more susceptible to the accelerator effect of changes in aggregate demand generated by tax rate changes; as a result one would expect such firms to have larger profit rate changes in response to tax rate changes. And a third reason might be that different tax rates affect the amount of tax incidence shifting in high monopoly power firms more than in low monopoly power firms.

\section{CONCLUSIONS}

It is clear from these results that the separation of ownership from control can be effective only among firms with a high degree of monopoly power. It is also apparent that the managers of weak owner controlled firms, and to a lesser extent of management controlled firms, are usually near the margins with respect to their decisions dictated by inequality (3) since they report larger profit rate changes in response to tax rate changes than do strong owner controlled firms. It would appear that these managers find the $P_{c}$ and $s$ terms of inequality (3) to be in an intermediate range such that rather minor changes in tax rates are sufficient to induce them to change their behaviour, while the managers of strong owner controlled corporations have made inframarginal decisions to select the left side of (3). Furthermore, it seems plausible that management controlled corporations had no larger response than they did because many of their managers were also making inframarginal decisions, but on the right side of (3). 
Table 1. Average Response of Profit Rates to Tax Rate Changes

\begin{tabular}{|c|c|c|c|c|}
\hline Degree of & & Type & Control & \\
\hline $\begin{array}{l}\text { Monopoly } \\
\text { Power }\end{array}$ & $\begin{array}{l}\text { A11 Types } \\
\text { of Control }\end{array}$ & Management & Weak Owner & Strong Owner \\
\hline $\begin{array}{l}\text { A11 degrees of } \\
\text { monopoly power }\end{array}$ & 2.00 & 2.06 & 2.12 & 1.53 \\
\hline Low & 1.42 & 1.28 & 1.90 & 1.34 \\
\hline Medium & 2.17 & 2.31 & 1.93 & I. 76 \\
\hline High & 2.52 & 2.58 & 3.13 & 1.31 \\
\hline
\end{tabular}


Table 2. Some Comparisons of Profit Rate Responses

To Tax Rate Changes

Comparison

1. Ignoring degree of monopoly power:

management vs, strong owner

management and weak owner vs. strong owner

2. Ignoring type of control:

low monopoly power vs. medium monopoly power

low monopoly power vs. high monopoly power

low monopoly power vs. medium and high monopoly power

3. Among firms with low monopoly power:

management vs. weak owner

weak owner vs. strong owner

16

11

1.024

1.064

4. Among firms with medium monopoly power:

management vs. weak owner

management vs. strong owner
3.188

2.843

$4.265 *$
1.965

3.165

$\mathbf{F}$

45

112

398$$
1.064
$$

19

0.488

0.982

5. Among firms with high monopoly power:

management vs. weak owner

management vs. strong owner

2

43

16

weak owner vs. strong owner

34

0.343

1.892

$6.116 *$

$5.089 \%$

* Statistically significant at the $5 \%$ level or less for a one-tailed test. 
[1] Adolph Berle, "The Impact of the Corporation on Classical Economic Theory," Q.J.E. (1965) 79: 26-40.

[2] R. Cyert and J. March, A Behavioral Theory of the Firm. Englewood Cliffs, N.J., Prentice-Ha11, Inc. 1963.

[3] J. W. Elliot, "Control, Size, Growth, and Financial Performance in the Firm," Journal of Financial and Quantitative Analys is (Jan. 1972): 1309-1320.

[4] David Kamerschen, "The Influence of Ownership and Control on Profit Rates," A.E.R. (1968) 58: 432-447.

[5] Robert Larner, Management Control and the Large Corporation. New York, Dunellen, 1970.

[6] Wilbur Lewellyn, The Ownership Income of Management. New York, N.B.E.R. 1971 .

[7] Robin Marris, "A Mode1 of the 'Managerial' Enterprise," Q.J.E. (1963) 77: 185-209.

[8] Robert Masson, "Executive Motivations, Earnings, and Consequent Equity Performance," J.P.E. (1971): 1278-1292.

[9] R. Monsen, J. Chiu, and D. Cooley, "The Effect of Separation of Ownership and Control on the Performance of the Large Firm," Q.J.E. (1968) 82: 435-451. and A. Downs, "A Theory of Large Managerial Firms," J.P.E. (1965) 73: 221-236.

[11] Bernard 0st1e, Statistics in Research, 2nd ed. Ames, Iowa, The Iowa State University Press, 1963. 
[12] John Palmer, "The Profit-Performance Effects of the Separation of Ownership from Control in Large U.S. Industrial Corporations," The Bell Journal of Economics and Management Science (1973, forthcoming).

[13] , "The Extent of the Separation of Ownership from Control

in Large U.S. Industrial Corporations," Quart. Rev. of Ec. and Bus. (1972) $12: 55-62$.

[14] Oliver Williamson, The Economics of Discretionary Behavior: Managerial Objectives in a Theory of the Firm. Englewood Cliffs, N.J., Prentice-Ha11, Inc. 1963. 